\title{
DAMPING LOSS FACTOR ESTIMATION BY EXPERIMENTAL METHOD FOR PLATE WITH CONVETIONAL AND COMPOSITE MATERIALS
}

\author{
M.B.Mandale ${ }^{1}$,Dr.P.Bangarubabu ${ }^{2}$ and Dr.S.M.Sawant ${ }^{3}$ \\ ${ }^{1}$ Research Scholar, Department of Mechanical Engineering, N.I.T.Warangal, India. \\ 2Professor, Department of Mechanical Engineering, N.I.T.Warangal, India \\ ${ }^{3}$ Professor, Department of Mechanical Engineering, R.I.T.Sakharale, India \\ Email-maruti.mandale@ritindia.edu
}

\begin{abstract}
Statistical Energy Analysis is extensively used framework for predicting the transmission of vibration and sound through complex structures. The prediction of noise and vibration levels in such structures depends on precise estimation of three parameters viz. modal densities, the damping loss factors and the coupling loss factors between the subsystems. Damping is usually characterized by the amount of energy dissipated and the most common measure of this dissipation is damping loss factor. This paper describes the effect of materials used for plate on damping loss factor. The experimental results of conventional and composite plates are compared. Damping loss factor has been determined by Half-power bandwidth method for the plates.
\end{abstract}

Keywords: Statistical Energy Analysis, Damping Loss Factor, Half Power Bandwidth Method

\section{Introduction}

Statistical energy analysis (S.E.A) is a method for high frequency noise and vibration analysis. It is applicable to complex structures which are built up from subsystems coupled together. For any mechanical systems lower modes of vibrations are important in conventional vibration analysis because at these modes the amplitude of vibration is higher. The large light weight aerospace structures are subjected to high frequency loads, so it is necessary to find out the dynamic behaviour of the system even for higher modes of vibration to avoid system failure, structural fatigue and generation of noise. SEA has been extensively used in a growing number of applications such as airplanes, large machines, buildings, ships, space vehicles etc.for predicting the vibration amplitudes and sound pressures [6].

SEA model can be analysed by three basic parameters, those are Damping loss factor, modal density and coupling loss factor. Modal density is considered to group the resonant modes into different frequency bands while damping loss factor and coupling loss factor are considered as energy transfer parameter. Energy of vibration gets accumulated in the vibrating structures in the form of kinematical energy and potential energy. The vibrating structures radiate and dissipate the energy. Damping loss factor can be defined as ratio of amount of energy dissipated per radian to the total energy of the system. It can be determined by three methods; those are decay rate method, power injection method and half power bandwidth method. The objective of the work is to estimate damping loss factor of plate made of conventional materials and composite plates by using half power bandwidth method.

\section{Experimental Results}

Damping loss factor is represented in a SEA power balance equation for an isolated subsystem by

$$
\pi_{\text {in }}=\pi_{\text {diss }}=2 \pi f n E_{\text {tot }}
$$

Where $\pi_{\text {in }}$ is the input power, $\pi_{\text {diss }}$ is the dissipated power, and $E_{\text {tot }}$ is the total energy of the dynamical response in the subsystem at frequency $f$ $(\mathrm{Hz})$. The quantity $2 \pi n$ is the ratio of energy dissipated per cycle of oscillation to the total energy in the subsystem. Decay rate method, half power bandwidth method and Power injection method are most commonly used methods for estimation of damping loss factor.[6]

\subsection{Half Power Bandwidth method:}

The most common method of determining damping is to measure frequency bandwidth between points on the response curve, for which the response is some fraction of the resonance of the system. The two points are located at frequencies on the response curve where the amplitude of response of these points is $\frac{1}{\sqrt{2}}$ times the maximum amplitude. The bandwidth at these points is frequently referred as 'half-power bandwidth' [5]. The frequency interval 
between these two half-power points is $\Delta \omega=\omega_{2}-$ $\omega_{1}$.Damping loss factor of this method is defined as,

$$
n=\frac{\Delta \omega}{\omega_{n}}
$$

Experimental setup used for measurement of DLF is shown in figure 1. Here the test specimens are plates made up of different material like mild steel, aluminium and stainles steel. Physical dimensions of plates are illustrated in Table 2.1. The plates were hanged to the frame with the help of threads. The plates were excited with hammer. The accelerometer was mounted at the centre of plate. The hammer input and accelerometer output signal were given to the FFT analyser.

After hammer excitation the different spectrums were recorded by the software, out of them Amplitude Vs Frequency spectrum was used to evaluate damping loss factor at different frequencies.

Table.2.1. Test specimen details

\begin{tabular}{ccc}
\hline $\begin{array}{r}\text { Sr } \\
\text { No. }\end{array}$ & Material & Dimensions $(\mathrm{mm})$ \\
\hline $\mathbf{1}$ & Mild steel & $305 \times 400 \times 2$ \\
$\mathbf{2}$ & Aluminium & $305 \times 400 \times 2$ \\
$\mathbf{3}$ & Stainless steel & $305 \times 400 \times 2$ \\
\hline
\end{tabular}

Maximum amplitude $(A)=396.469 \mathrm{~nm}$

$\frac{A}{\sqrt{2}}=\frac{396.469}{\sqrt{2}}=280.3486 \mathrm{~nm}$

$\omega_{1}=47.5936 \mathrm{~Hz}$

$n=\frac{\left(\omega_{2}-\omega_{1}\right)}{\omega_{n}}$

$\omega_{2}=53.8395 \mathrm{~Hz}$

$\omega_{n}=50 \mathrm{~Hz}$

$n=0.12492$

Simply supported condition of plate was achieved by using the special arrangement, that was the metal frame having bolts for tightning purpose . The plate was placed in that frame and accelerometer was mounted at the centre of plate. The excitation to that plate was given by hammer and by using the FFT analyzer the data were recorded.

Cantilever condition of plate was achieved by using the same arrangement which was used for simply supported condition. Only one edge of the plate was fixed with the help of bolts. Accelerometer was mounted at the centre of the plate. The same test specimens were used for this condition. The excitation to that plate was given by hammer and by using the FFT analyzer the data were recorded.

Six composite specimens were tested to evaluate Damping Loss Factor with free free condition.

\section{Results and Discussion}

The results of damping loss factor were compared for Mild Steel, Aluminium and Stainless Steel simply supported and cantilever plate as shown in figures 3 and 4 . It has been observed that, at lower frequencies the value of damping loss factor decreases drastically while at higher frequencies it remains fairly constant. Damping loss factor is less of mild steel plate as compare to aluminum and stainless steel plates for simply supported and cantilever condition. It has been observed that, for every plate made up of conventional materials the value of damping loss factor is high for simply supported condition than cantilever condition.

In comparison with composite plate and plate made up of conventional materials, it has been observed that at low frequencies there is drastic change between DLF values. The DLF values of composite plate are considerably greater than plates made up with conventional materials. The value of DLF of composite plate is always higher than that of plate made up with conventional materials for considered frequency range as shown in figures 5 and 6 . In comparison among the composite plates with different fiber orientations, the DLF value of plate with unidirectional fiber orientation is always lower than the plates with cross ply and quasi isotropic orientations. It has also been observed that the value of DLF of plate with quasi isotropic orientation is always higher than the plates with unidirectional and cross ply orientations. 


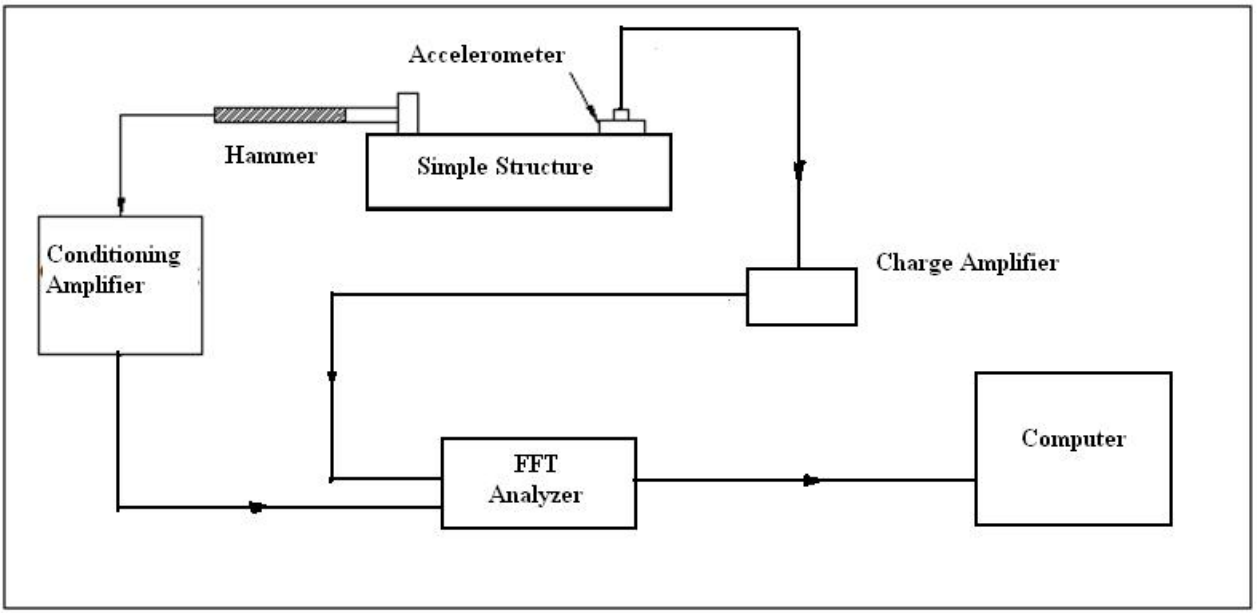

Figure1. Schematic block diagram of the test rig to determine damping loss factor

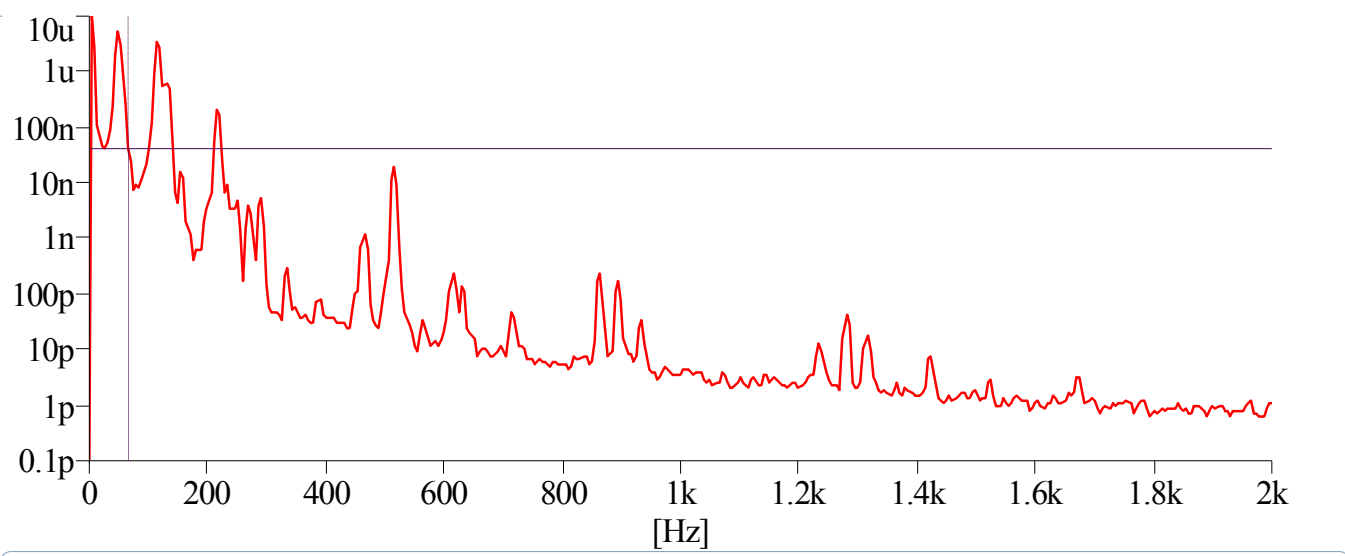

Curs or values $\mathrm{X}: 65.000 \mathrm{~Hz}$ Y: 43.291n m

Autospectrum(1 Scalar,) - Input (Real) $\backslash$ FFT

Figure 2. Amplitude Vs Frequency for Mild steel plate

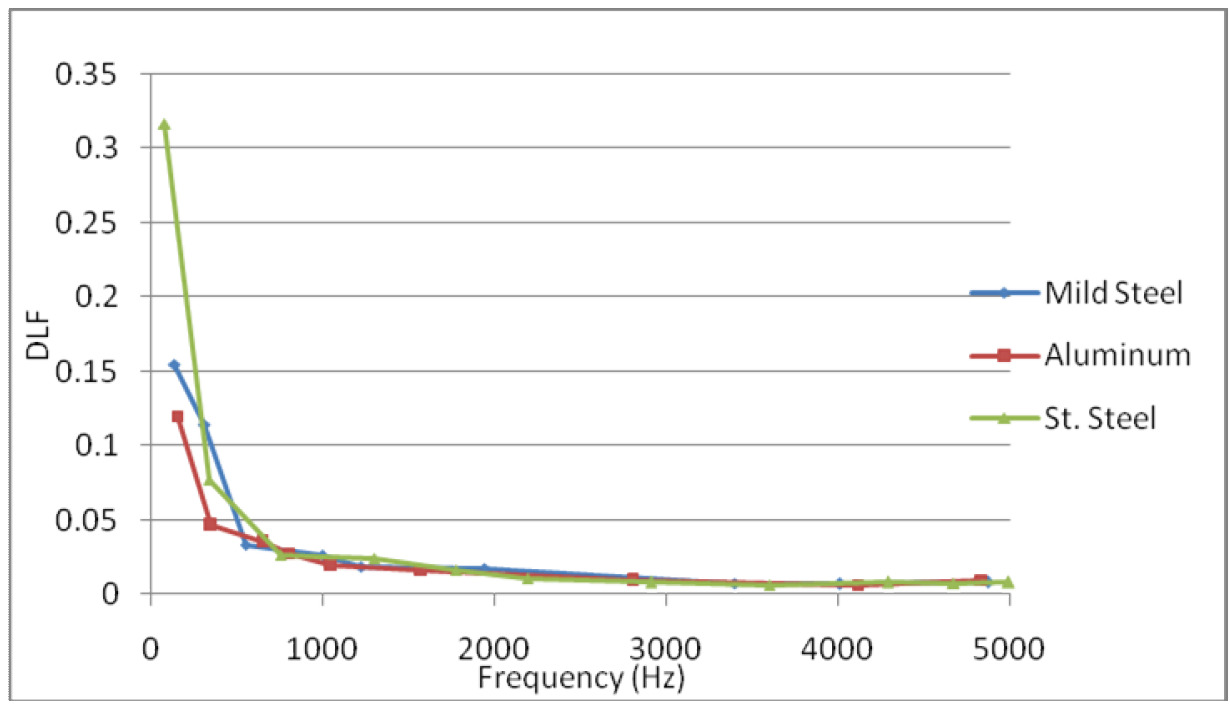

Figure 3. Damping loss factors for simply supported plates 


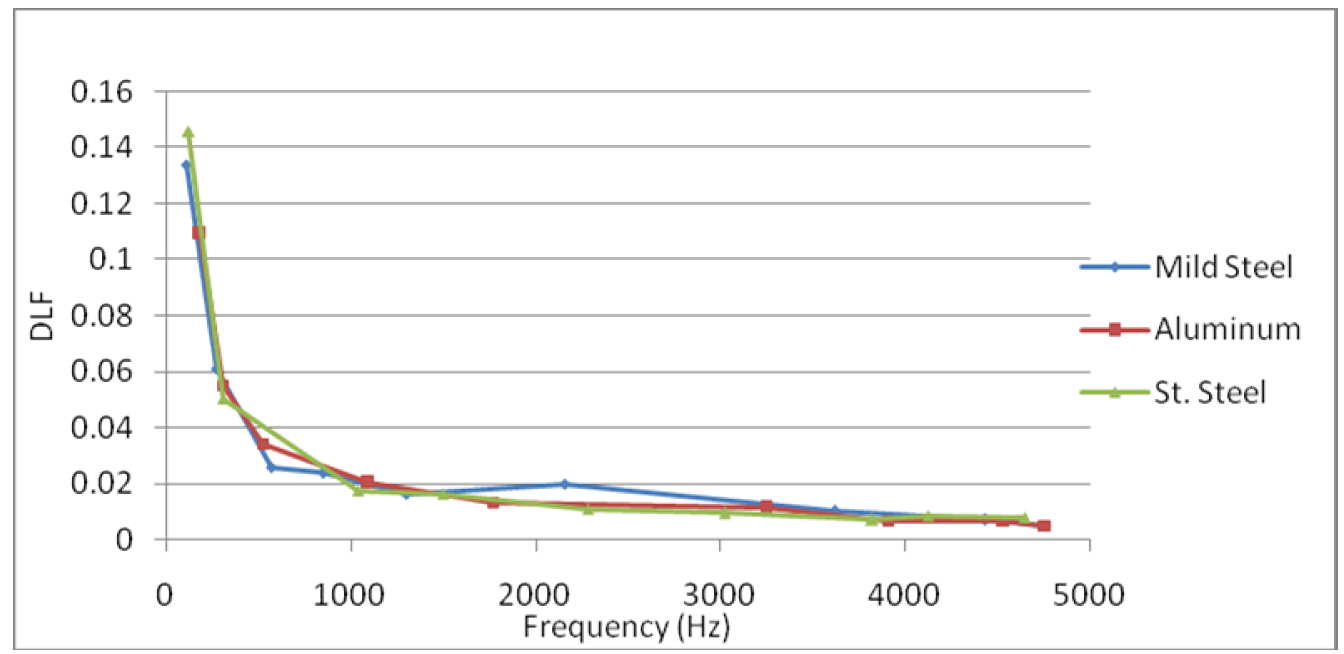

Figure 4. Damping loss factors for cantilever plates

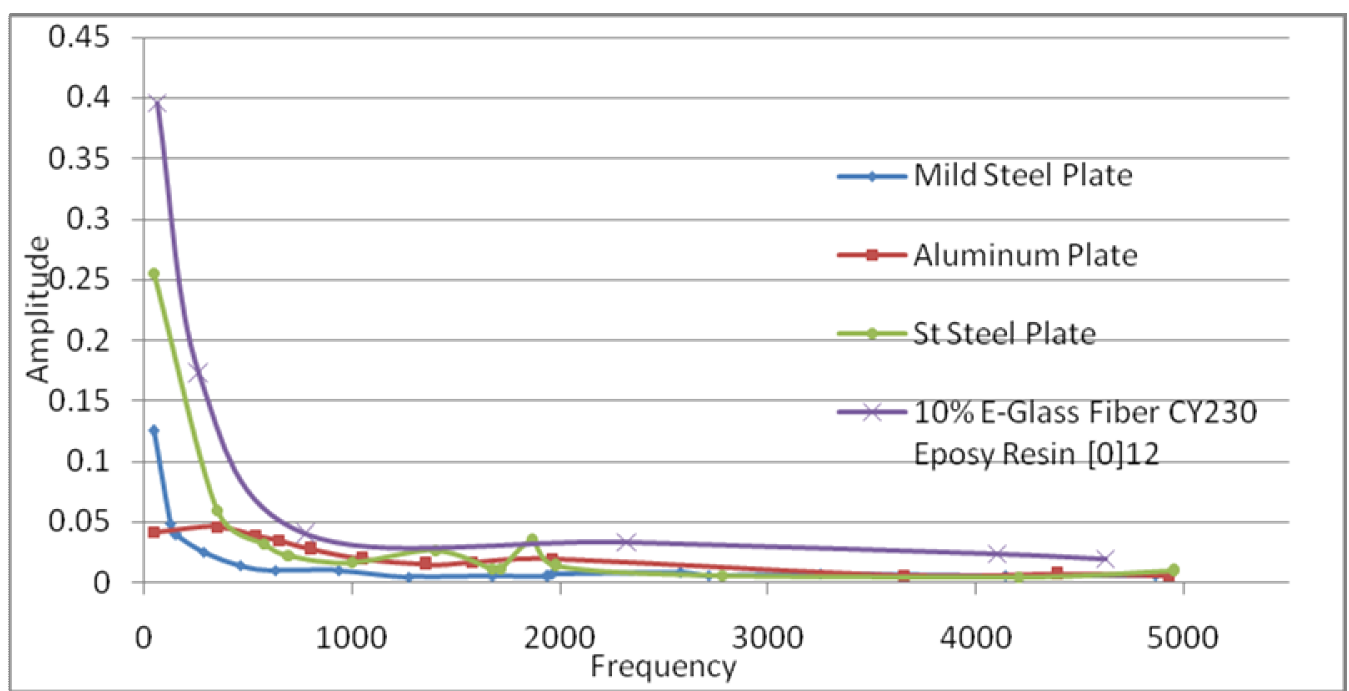

Figure 5. Comparison between conventional and composite plate-1

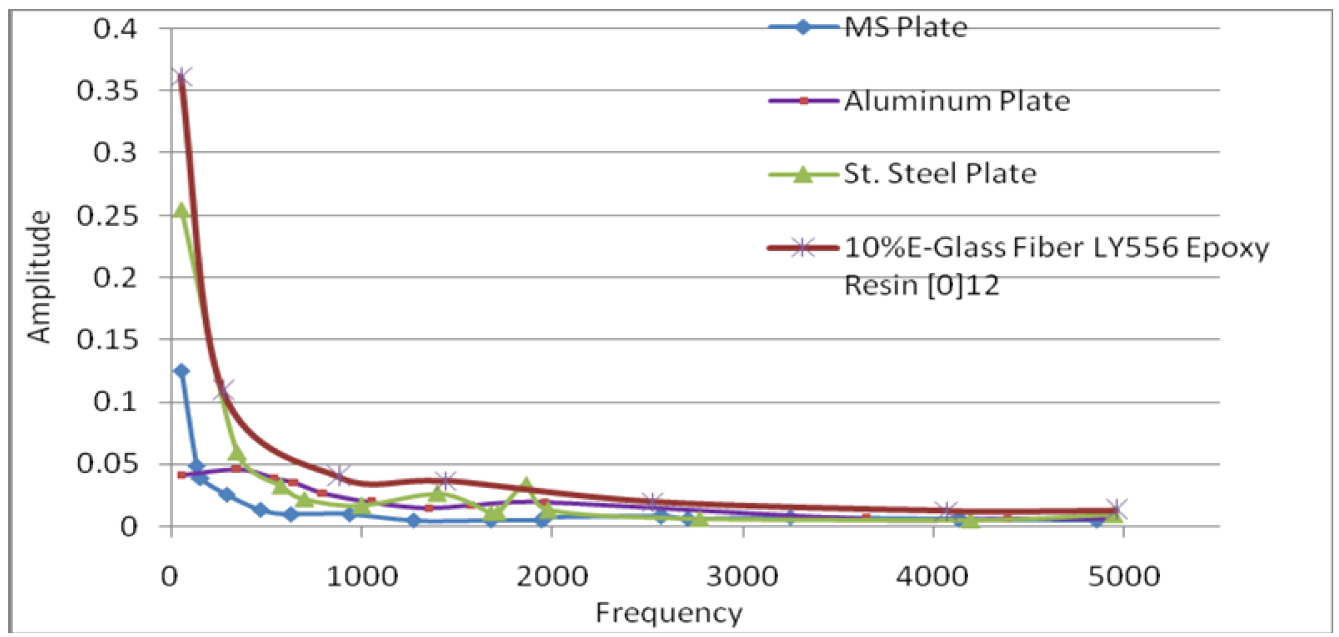

Figure 6. Comparison between conventional and composite plate-2 


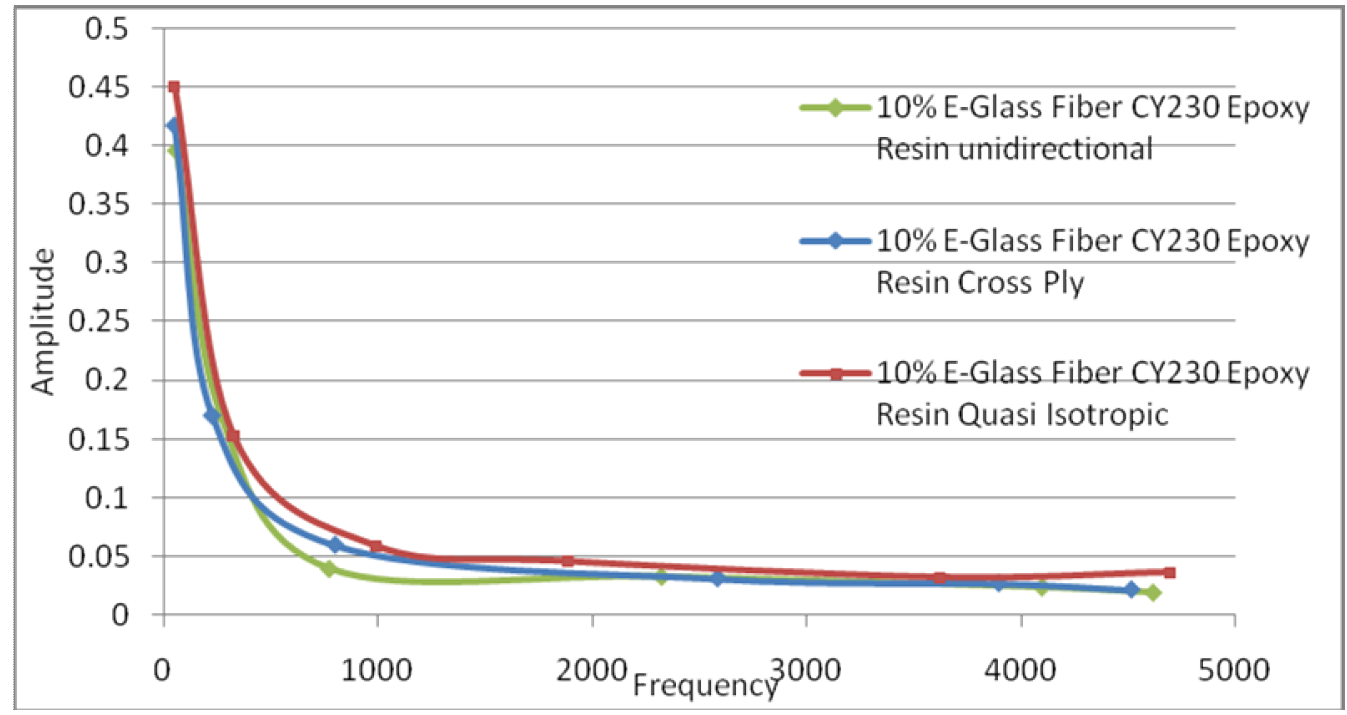

Figure 7. Comparison of composite plate-1 with different fiber orientation

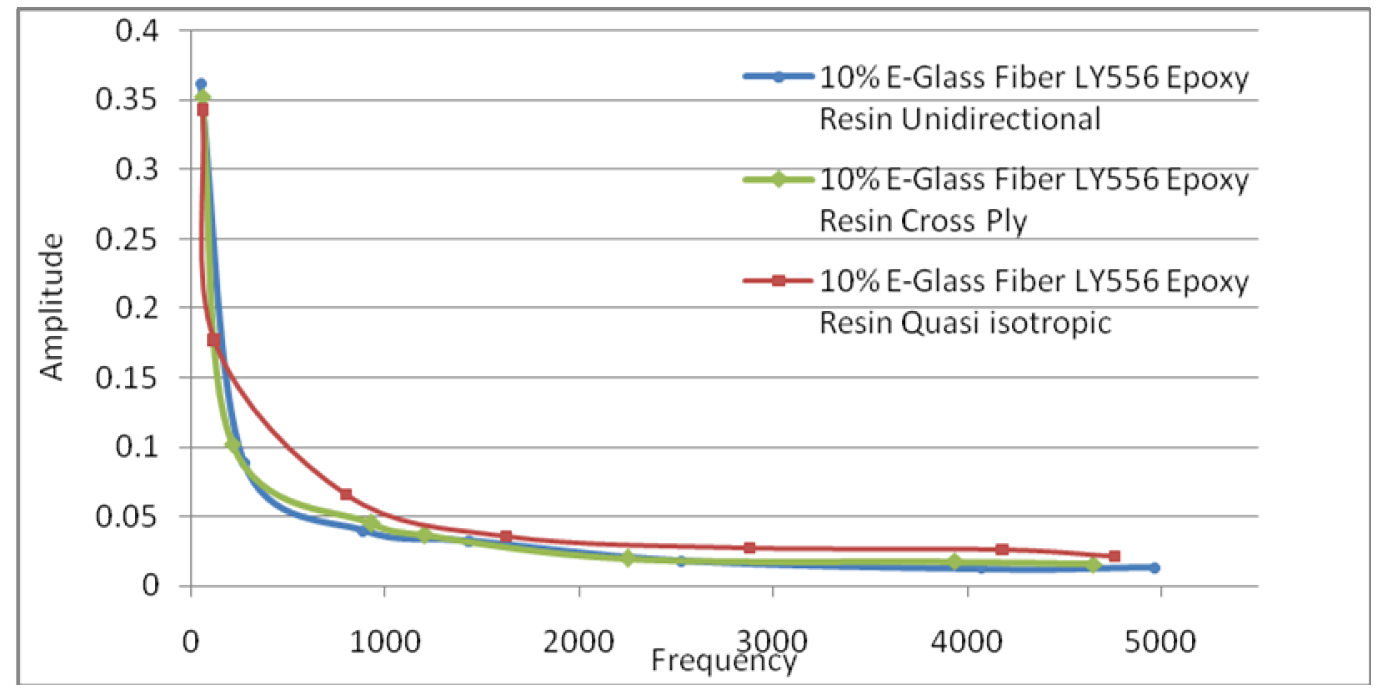

Figure 8. Comparison of composite plate-2 with different fiber orientation

\section{Conclusion}

This paper describes experimental estimation of damping loss factor (DLF) of plates by half power bandwidth method. As the damping cannot be measured directly, it is usually estimated from the response curves of the vibrating system.Due to higher damping loss factor, more vibration energy was absorbed in plates. The following conclusions have been obtained:

1) As frequency increases damping loss factor decreases. At higher frequency damping loss factor is lower because of low amplitude of vibration. At lower frequencies the value of damping loss factor decreases drastically while at higher frequencies it remains fairly constant. 2) Damping loss factor value changes with material and it helps to select suitable material for particular application.3) Damping loss factor of composite material is higher than conventional materials so conventional materials can be replaced with composite materials to get better results. 4) Fiber orientations of the composite material also have significant impact on Damping Loss Factor as quasi isotropic orientation gives more DLF value 
as compared to other orientations taken in to consideration.

\section{References}

1. Abdullah Secgin, (2013), "Numerical determination of statistical energy analysis parameters of directly coupled composite plates using a modal based approach", Journal of sound and vibration, 332 pp.361-377.

2. A. Wang, X. Yin, X. Li and L. Chen,(July 2013), "Numerical and experimental study on modal damping loss factor of structural panels with damping treatments", $2^{\text {th }}$ International congress on Sound and vibration.

3. Ahmed Maher, Fawkia Ramadan, Mohamed Ferra, (1999), "Modeling of vibration damping in composite structures", Journal of Composite structures $46 \mathrm{pp}$. 163-170.

4. Marek Iwaniec, (2003), "Damping loss factor estimation in plates", Journal of Molecular and Quantum Acoustics vol. 24,. pp. 437-442.

5. Nirmal Kumar Mandal, Roslan Abd. Rahman, M. Salman Leong, (2004), "Experimental study on loss factor for corrugated plates by bandwidth method", Ocean Engineering 31 pp. 1313-1323.

6. R.H. Lyon, R.G. Dejong, (1995),"Theory and Application of Statistical Energy Analysis", Second edition, Butterworth-Heinemann, London,

7. Ya-nan Xu, Qiong Deng and Long Feng, (2013) "The damping characteristics analysis of a beam using constrained Layer Damping", 9th International Conference on Fracture \& Strength of Solids, Jeju, Korea. 